\title{
5 TIMES SIT-TO-STAND TEST PERFORMANCE IN DIFFERENT CATEGORY OF UNILATERAL AND BILATERAL KNEE OSTEOARTHRITIS PATIENTS
}

\author{
Dr. Manoj kumar ${ }^{1}$, Dr. Dipti padole, ${ }^{2}$ Dr. Chaitany Patel $^{3}$,ArjunPanchal,Nisarg Raval ${ }^{4}$
}

${ }^{1}$ Principal, Shree B. G. Patel College of Physiotherapy

${ }^{2}$ Associate Professor, Shree B. G. Patel College of Physiotherapy

${ }^{3}$ Assistant Professor, Shree B. G. Patel College of Physiotherapy

${ }^{4}$ Intern, Shree B. G. Patel College of Physiotherapy

Affiliated to Sardar Patel University,Anand-388001

Corresponding author: Dr.chaitanypatel Email: chaitany.bpt@gmail.com

ABSTRACT: PURPOSE: To obtain the normal time period for 5 time sit-to-stand indifferent category of unilateral and bilateral knee osteoarthritis patients. OBJECTIVES: To study the influence of 5 Time Sit-To-Stand Test in different category of unilateral and bilateral knee osteoarthritis patients and The effect of unilateral OA and bilateral OA on the FTSTST performance.METHODS:Cross Sectional Study design assigned by convenient samplingwith150Subjects in each group.OUTCOME MEASURE: Five times sit to stand test, WOMAC Scale RESULTS: The average FTSTS times in unilateral OA range from $\mathbf{1 3 . 4}$ to 23.6 sec. and bilateral OA patient range from 15.4 to 27.8 sec.CONCLUSION:There is significance of the observed relationship between unilateral OA and bilateral OA basis on different category of WOMAC score with FTSTS times. There is significance effect of unilateral OA and bilateral OA on the FTSTST performance.So we conclude the influence on different category of unilateral OA and bilateral OA patients on five time sit to stand test performance.

Keywords: sit to stand, five times sit to stand test, osteoarthritis knee, OA knee, WOMAC scale, unilateral knee OA, bilateral knee OA

INTRODUCTION: Osteoarthritis (OA), also known as degenerative arthritis or degenerative joint disease or osteoarthrosis, is a group of mechanical abnormalities involving degradation of joints (Osteoarthritis, 2001) including articular cartilage and subchondral bone. ${ }^{1}$
Globally over 100 million people worldwide suffer from Osteoarthritis and is the fourth leading cause of year lived with disability (YLDs), accounting for 3.0\% of total global YLDs. ${ }^{2}$ 
It also accounts for the decrease in activities of daily living (ADL) in elderly dependent population in the community. ${ }^{3}$

$\mathrm{OA}$ is strongly associated with ageing and the Asian region is ageing rapidly. In India, $8 \%$ of total population are above 60 years in 2010 and is likely to rise to $21 \%$ by $2050 .{ }^{4}$

Osteoarthritis most often affects middle-age to elderly people. It is commonly referred to as OA or as "wear and tear" of the joints, but we now know that OA is a disease of the entire joint, involving the cartilage, joint lining, ligaments, and bone. OA is one of the leading causes of disability in older people. A variety of causes like developmental, hereditary, metabolic, and mechanical defects may initiate processes leading to loss of cartilage. When bone surfaces become less well protected by cartilage, bone may be denuded and damaged. As a result of decreased movement secondary to pain, regional muscles may atrophy, and ligaments may become more lax. Symptoms may include joint pain, tenderness, stiffness, locking, and sometimes an effusion. This arthritis tends to occur in the hand joints, spine, hips, knees, and great toes. OA symptoms can vary greatly among patients.

Diagnosis is made with reasonable certainty based on history and clinical examination (Zhang, et al., 2010; BiermaZeinstra et al., 2002). ${ }^{\mathbf{5}}$

X-rays may confirm the diagnosis. Clinically OA can be graded with the help of the WOMAC grading which is a direct measure of the severity of symptoms of OA. This can be used as a good screening tool as well as a good way to accurately measure the response to treatment.

Alterations in functional movement patterns have been noted in patients with knee osteoarthritis (OA), characterized by compensations to reduce loading of the affected limb. ${ }^{6-9}$ The weight-bearing asymmetry (WBA) created by these altered movement patterns has been documented during performance of common daily tasks such as walking3 and stair climbing.

Transitions between sitting and standing are fundamental to daily activity and identified as a key functional problem for people with knee impairment. ${ }^{\mathbf{1 0 , 1 1}}$ There is indication that WBA may be problematic during transitions between sitting and standing for people with unilateral knee OA.

The WOMAC (Western Ontario and McMaster Universities) osteoarthritis index 5-point Likert version was used to detect patients for OA. The WOMAC index is the best validated and most widely used 
outcome measure in subjects with knee osteoarthritis. ${ }^{12,13}$

It is a 24 item questionnaire focusing on pain, stiffness, and functional limitation. ${ }^{14}$ In the Likert version, each item offers 5 responses: "none" scored as 0 , "mild" as 1 , "moderate" as 2, "severe" as 3, and "extreme" as 4. The total score for each subscale is the sum of scores for each response to each item, and can be calculated manually or using a computer. The range for possible subscale scores in the Likert format are: pain $(0-20 ; 5$ items each scored0-4), stiffness (2 items, 0-8), and physical function (17 items, 0-68). Higher scores indicate worse pain, stiffness, or physical function. The maximum score obtained by the subjects would be 96. Based on the WOMAC score obtained, patients were categorized as low risk (score $\leq 60$ ), moderate risk (score 60-80) and high risk (score $\geq 81$ ). WOMAC scores is also expressed as percentages and categorized into low risk $(\leq 70 \%)$ and high risk $(>70 \%)$.

The five times sit to stand test was designed by Csuka and McCarty in 1985. It is used to assess the functional muscle strength of the lower limb, especially with older adults. The subject is instructed to stand up from sitting for five times as quickly as possible without using the hands for support. The total duration recorded in seconds. ${ }^{15}$

We hypothesized the five time sit to stand time perform in unilateral $\mathrm{OA}$ and bilateral OA patients and correlate with the WOMAC score to see the influence on the FTSTS perform so we conduct study.

MATERIAL AND METHODOLOGY STUDY DESIGN :Cross Sectional Study STUDY SETTING: Department of Physiotherapy, SHREE B.G PATEL COLLAGE OF PHYSIOTHERAPY,ANAND, GunatitJyot Foundation, Vidhya Dairy Employee and Senior Citizen Club Visamo Garden

SAMPLE SIZE: 300 subjects total population in this study and 150 patients in each group

SUBJECTS: Male and female

INCLUSION CRITERIA:

1. 50 to 75 years

2. $\leq 35 \mathrm{kgm}^{-2} \mathrm{BMI}$

3. No palpable warmth

4. Independent sit to stand perform

\section{EXCLUSION CRITERIA:}

1. Any under gone any lower limb surgery 
2. Other condition like rheumatoid arthritis

3. Medically unstable or known condition as sever hypertensive

4. Any neurological complication

5. 2 or more pain items, both stiffness items, and 4 or more physical function items are missing, the response is regarded as invalid and the deficient subscale(s) is not included in analysis.

\section{MATERIALS USED IN STUDY:}

Pen, Pencil, rubber, Paper ,Measure tape

\section{APPARATUS USED IN STUDY:}

Height adjustable chair, Digital stop watch, Weight machine, Height chart

OUTCOME MEASURES:

5 Time Sit To Stand Test (FTSTS) :WOMAC SCALE :-

\begin{tabular}{|c|c|}
\hline Category & Score \\
\hline Low risk & $\leq 60$ \\
\hline Moderate risk & 61 to 80 \\
\hline High risk & $\geq 81$ \\
\hline
\end{tabular}

\section{PROCEDURE}

Subjects will be selected on the basis of inclusion and exclusion criteria. All subjects will be provided written informed consent.
A high adjustable chair was used in this study to ensure subject's hip was in $90^{\circ}$ flexion when seated. The subjects were instructed to stand up and sit down from hight adjustable chair 5 times as quickly as they could.

The standardized instruction give for each trial was "on the count of 3 ,please stand up and sit down 5 times as fast as you can.” The timing started when the subject's back left the back rest and ended when their back touched the back rest after the $5^{\text {th }}$ repetition. The time was recorded by hand using a digital stop watch.

Seat height was adjusted according to their lower leg length in all trials. The lower leg length was defined as the perpendicular distance between the fibular head and the floor, when the subject sat on the chair with the knees in $90^{\circ}$ of flexion and the ankles in the neutral position. 
In this study mainly chair height $36 \mathrm{~cm}$ to 46 $\mathrm{cm}$ is used during the five time sit to stand test performance.

\section{STATISTICAL ANALYSIS}

Two-way repeated measures ANOVA were conducted to examine the significance of the observed relationship between unilateral OA and bilateral OA basis on different category of WOMAC score with FTSTS times.

If the main effects of unilateral $\mathrm{OA}$ and bilateral OA on the FTSTST performance were statistically significant, post hoc multiple comparison test with Bonferroni adjustment would be used to evaluate the differences of FTSTS times between the different category of WOMAC score.

Independent $t$ test for find out of the influence on different category of unilateral OA and bilateral OA patients on FTSTST.

Null hypothesis will be rejected if $P<0.05$. All the statistical analysis was conducted with the help of version 16.0 of the SPSS.

\section{RESULT}

All the descriptive characteristics of the subjects and their variables are analysed.

Total 300 patients were taken so according each variables distribution and differences is seen

\begin{tabular}{|l|l|l|l|}
\hline \multicolumn{2}{|l|}{ GENDER } & \multicolumn{2}{l|}{ UNILATERAL OA } \\
SIDE \\
\hline MALE & FEMALE & RIGHT & LEFT \\
\hline 94 & 206 & 83 & 67 \\
\hline
\end{tabular}

TABLE NO. 2

\begin{tabular}{|l|l|}
\hline VARIABLES & MEAN \pm SD \\
\hline AGE (Year) & $61.5 \pm 8.89$ \\
HEIGHT & $163 \pm 7.5$ \\
WOm) & $68 \pm 8.6$ \\
(KOD) & \\
\hline BMI( kgm-2) & $27.5 \pm 4.5$ \\
\hline $\begin{array}{l}\text { SINCE HOW } \\
\text { LONG(Years) }\end{array}$ & $5.2 \pm 6.5$ \\
\hline
\end{tabular}


Demographic characterizes of the $\mathbf{3 0 0}$ subjects are shown Table No 1 and Table No.2.

Their mean age was $61.5 \pm 8.89$ years , and average duration of OA $5.2 \pm 6.5 y e a r s$.

Their subjects mean BMI (kgm-2) was 24.35 $\pm \mathbf{3 . 5 5}$ so category normal to overweight.

\begin{tabular}{|c|c|c|c|}
\hline $\begin{array}{l}\text { WOMAC SCORE } \\
\text { GREADING }\end{array}$ & $\begin{array}{l}\text { UNILATERA } \\
\text { L KNEE OA }\end{array}$ & $\begin{array}{c}\text { BILATER } \\
\text { AL KNEE } \\
\text { OA }\end{array}$ & $\begin{array}{c}\text { Compariso } \\
\mathrm{n} \text { and } \\
\text { result }\end{array}$ \\
\hline LOW RISK & $13.44 \pm 2.5$ & $\begin{array}{c}15.48 \pm \\
3.79\end{array}$ & $\begin{array}{l}\mathrm{t}=3.174 \\
\mathrm{df}=98 \\
\mathrm{P}<0.0020\end{array}$ \\
\hline $\begin{array}{l}\text { MODERATE } \\
\text { RISK }\end{array}$ & $17.79 \pm 4.08$ & $\begin{array}{c}18.79 \pm \\
4.18\end{array}$ & $\begin{array}{l}\mathrm{t}=1.208 \\
\mathrm{df}=98 \\
\mathrm{P}<0.2098\end{array}$ \\
\hline HIGH RISK & $23.63 \pm 1.85$ & $\begin{array}{c}27.08 \pm \\
1.24\end{array}$ & $\begin{array}{c}\mathrm{t}=10.89 \\
\mathrm{df}=98 \\
\mathrm{P}<0.0001\end{array}$ \\
\hline $\begin{array}{c}\text { Comparison and } \\
\text { result }\end{array}$ & $\begin{array}{r}\mathrm{F}=123.76, \\
\mathrm{DFd}=2 \\
\mathrm{P}<0.0\end{array}$ & $\begin{array}{l}\mathrm{DFn}=5, \\
45 \\
001\end{array}$ & \\
\hline
\end{tabular}

TABLE NO. 3

5 TIME SIT-TO-STAND TEST TIMES (SES)

Both the main effect of foot placement and arm position were statistically significant with $\quad F=\quad$ 123.76,DFn=5, $\quad$ DFd $=245$

$\mathbf{P}<\mathbf{0 . 0 0 0 1}$.

GRAPH NO. $3($ T-3)

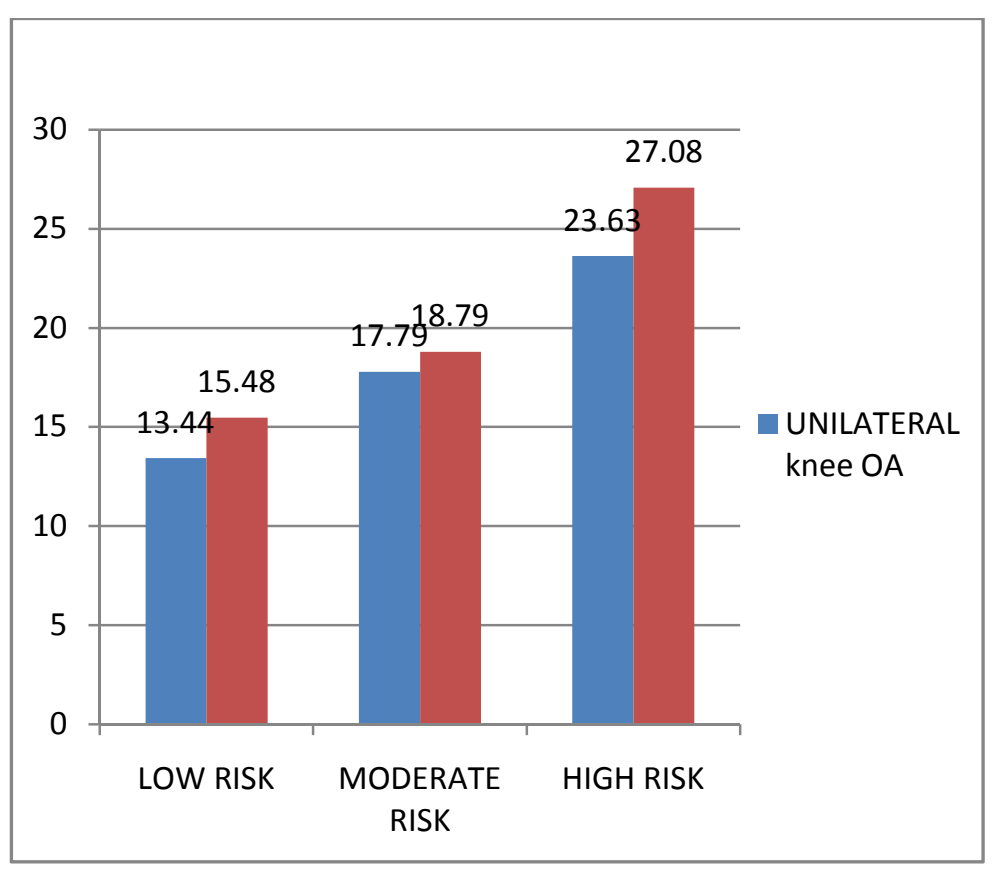

Here two way ANOVA repeated measures test is used. Table no. 3 the average FTSTS TIMES with the different between unilateral $\mathrm{OA}$ and bilateral $\mathrm{OA}$ basis on different category of WOMAC score. The mean FTSTS times ranged from 13.44 to 27.08 seconds.

Discussion: This study was intended to investigate to influence of Five Time Sit To Stand different category of unilateral and bilateral knee osteoarthritis patients. Our results showed that the unilateral and bilateral knee osteoarthritis could affect 
FTSTS times. WOMAC score category in low risk to high risk could affect FTSTS time.

Low risk of WOMAC score and unilateral OA patient taking less time.

The average FTSTS times in unilateral OA range from 13.4 to $23.6 \mathrm{sec}$. and bilateral OA patient range from 15.4 to $27.8 \mathrm{sec}$. This averages were comparable to those observed in previous studies that reported individual OA patient.

Cory L. Christiansen reported and stage of unilateral OA patient FTSTS time $13.3 \pm 3.7$ sec. but that study included in 50 subjects with min age $64.1 \pm 8.4$ year and end stage of OA define base on NPRS, In our study different stage of OA define base on WOMAC score category in form of low risk to high risk

S. Singh, V. Khanna reported WOMAC score and KL grade were associated of the age of patient. They both increased with the increasing age of the patient. There is strong positive correlation between KL grading and WOMAC score. In this study noted WOMAC score was min. 17 to max. 81 and the mean score is 51 .

So we compare our study womac score is min. 37 and max. 89 so that suggest the KL grade 2 to 4 is noticeable so different severity in study that's why the different seen in FTSTS time.

Bohannon (2006) had published a metaanalisis witch demonstrated that the normal FTSTS time.

Health individual age between 60 to 69 years was $11.4 \mathrm{sec}$. and 70 to 79 years was $12.6 \mathrm{sec}$.

It was aspected that our subject with OA patient would take longer duration to complete FTSTS. It might probebly be due to OA specific impairment such as pain, muscle weakness, stiffness and weight bearing asymmetry, impaired knee joint motion.

Schiphof at all (2013) morning stiffness is associated with knee pain I all grade of radiographic knee $\mathrm{OA}$ even $\mathrm{K} / \mathrm{L}$ grade 0 . This could indicate together with knee pain morning stiffness is an important symptom in early knee OA.

Adegoke BO at all found that participant with bilateral knee OA had significant more pain than participant unilateral knee OA.

In bilateral knee OA imparitmentsevierity and all factor contribute is more and which create reduced the physical performance and their relation in our study more time taken in five time sit to stand test performance in compare with unilateral knee OA. 
Boonstra MC at all Transitions between sitting and standing are fundamental to daily activity and identified as a key functional problem for people with knee impairment.There is indication that WBA may be problematic during transitions between sitting and standing for people with unilateral knee OA. ${ }^{21-23}$

It has been suggested that WBA is a response to unilateral knee pain in patients with OA.

Factors suggested to contribute to WBA include habitual movement pattern, impaired quadriceps femoris function and impaired knee joint motion. ${ }^{22,24-28}$

Cory L. Christiansen reported the weight bearing asymmetry during FTSTS time test seen in to the OA patient group and in that 18 of the 50 participants were unable to perform the FTSTS test without assistance of their upper extremity.

Bohannon at all (2010) investigate the relationship of isometric knee extension strength , age, gender, weight and FTSTS test performance in normal healthy individual. In all multiple regration method models knee extension strength provided the best explanation of FTSTS test performance. But age contributed as well their finding suggest FTSTS time reflex lower limb strength but that performance should be interpreted in light of age and other factor.

So we observed in our study the age is increase their relation muscle strength reduces so unilateral and bilateral knee OA other factors making influence on FTSTS test performance

\section{CONCLUSION}

There is significance of the observed relationship between unilateral $\mathrm{OA}$ and bilateral OA basis on different category of WOMAC score with FTSTS times.

There is significance effect of unilateral OA and bilateral OA on the FTSTST performance.

So we conclude the influence on different category of unilateral $\mathrm{OA}$ and bilateral OA patients on five time sit to stand test performance.

\section{LIMITATION OF STUDY}

- Design was cross sectional, No causal relationship can be established.

\section{CLINICAL IMPLICATION}

In individual following unilateral knee OA and bilateral knee OA. Some persistent common impairment such as pain muscle weakness poor weight bearing on affected side and reduce knee ROM due to knee OA 
impairment the functional limitation occur mainly In ADLs and BADLs

In this study mainly focus the sit to stand activity performance in knee OA patient.

Sit to stand done in various category of knee OA patients in that mainly low risk of unilateral OA patients shorter duration taken to complete the five time sit to stand.

The average FTSTS times in unilateral OA range from 13.4 to $23.6 \mathrm{sec}$. and bilateral OA patient range from 15.4 to $27.8 \mathrm{sec}$ given idea about time taken for FTSTS and diagnostic or normalcy create for patients.SS

\section{FUTURE RESEARCH}

- In view our study design was cross sectional no causel relationship can be established so change in study design and try to find out causal relationship.

Further study of the actual kinetic and kinematics of FTSTS with OA patient

\section{REFERENCE}

1. S. Singh, V. Khanna. Correlation between clinical and radiological grading of osteoarthritisScientific Journal of Medical Science (2014) 3(5) 320-324. ISSN 2322-5025 doi: 10.14196/sjms.v3.i5.1392.

2. World Health Organization. World Health Report 2002. Reducing Risks,
Promoting Healthy Life. Geneva: WHO; 2002.

3. Felson DT. The epidemiology of knee OA: results from the Framingham osteoarthritis study. Semin arthritis Rheum. 1990;20:42-50.

4. Rajan SI, Sarma PS, Mishra US. Demography of Indian aging, 20012051. J Aging Soc Policy. 2003;15:11-30.

5. Zhang, W., Doherty, M., Peat, G., Bierma-Zeinstra, M.A., Arden, N.K,,Bresnihan, B., Herrero-Beaumont, G., Kirschner, S., Leeb, B.F., Lohmander, L.S., Mazières, B., Pavelka, K., Punzi, L., So, A.K., Tuncer, T., Watt, I., Bijlsma, J.W., 2010. EULAR

6. Evidence-based recommendations for the diagnosis of knee osteoarthritis". Ann. Rheum. Dis., 69 (3), 483-9. doi,10.1136/ard.2009.113100.PMID 19762361.

7. Boonstra MC, Schwering PJ, De Waal Malefijt MC, Verdonschot N. Sit-tostand movement as a performancebased measure for patients with total knee arthroplasty. PhysTher 2010;90(2):149-56. [PubMed: 200076 64] Christiansen and Stevens-Lapsley Page 7 Arch Phys Med Rehabil. Author 
manuscript; available in PMC 2011

October 1.

8. Rudolph KS, Schmitt LC, Lewek MD. Age-related changes in strength, joint laxity, and walking patterns: are they related to knee osteoarthritis? PhysTher 2007;87(11):1422-32.

[PubMed:17785376]

9. Hurwitz DE, Ryals AR, Block JA, Sharma L, Schnitzer TJ, Andriacchi TP. Knee pain and joint loading in subjects with osteoarthritis of the knee. J Orthop Res 2000;18(4):572-9. [PubMed: 11052493]

10. Asay JL, Mundermann A, Andriacchi TP. Adaptive patterns of movement during stair climbing in patients with knee osteoarthritis. J Orthop Res. 2008

11. Su FC, Lai KA, Hong WH. Rising from chair after total knee arthroplasty.

ClinBiomech (Bristol,Avon) 1998;13(3):176-81.

12. Boonstra MC, De Waal Malefijt MC, Verdonschot N. How to quantify knee function after total knee arthroplasty? Knee 2008;15(5):390-5. [PubMed: 18620863]

13. Bellamy N, Buchanan WW, Goldsmith $\mathrm{CH}$, Campbell J, Stitt LW. Vakidation study of WOMAC: a health status instrument for measuring clinically important patient relevant outcomes to antirheumatic drug therapy in patients with OA of the hip or knee. J Rheumatol. 1988;15:1833-40.

14. Bischoff HA, Roos EM, Liang MH. Outcome assessment in osteoarthritis: a guide for research and clinical practice. In: Brandt KD, Doherty M, Lohmander LS, eds. OA New York: Oxford University Press, 2003:381-90.

15. Bellamy N. WOMAC: A 20-year experiential review of a patient-centered self reported health status questionnaire. J Rheumatol. 2002;29:2473-6.

16. M. Csuka and D.J.McCarty, "Simplemethod for measurement of lower extremity muscle strength," The American journal of medicine, vol. 78, no. 1, pp. 77-81, 1985.

17. R.W.Bohannon, M.E.Shove, S.R. Barreca, L.M.Masters, and C.S.Sinouin, "Five-repetition sit-to-stand test performance by community-dwelling adults: A preliminary investigation of times, determinants, and relationship with self reported physical performance," Isokinetics and Exercise Science, vol.15, no.2, pp.77-81,2007. 
18. R.W.Bohannon, "Reference values for the five-repetition sit-to-stand test: a descriptive meta-analysis of data from elders," Perceptual and Motor Skills, vol.103, no.1, pp. 215-222, 2006.

19. R.W.Bohannon, D.J.Bubela, S.R.Magasi, Y.-C.Wang, and R.C.Gershon, "Sit-to-stand test performance and determinants across the age-span," Isokinetics and Exercise Science, vol.18, no.4, pp. 235-240, 2010.

20. YoheiTakai, Megumi Ohta "Sit-to-stand test to evaluate knee extensor muscle size and strengthen the elderly: A Novel Approach," J PhysiolAnthropol 2009.

21. Cory L. Christiansen, and Jennifer E. Stevens-Lapsley.Weight-Bearing Asymmetry in Relation Measures of Impairment and Functional Mobility for People With Knee Osteoarthritis Arch Phys Med Rehabil. 2010 October ; 91(10): 1524-1528. doi:10.1016/j.apmr.2010.07.009

22. Su FC, Lai KA, Hong WH. Rising from chair after total knee arthroplasty. ClinBiomech (Bristol,Avon) 1998;13(3):176-81.

23. Boonstra MC, De Waal Malefijt MC, Verdonschot N. How to quantify knee function after total knee arthroplasty?
Knee 2008;15(5):390-5. [PubMed: 18620863]

24. Boonstra MC, Schwering PJ, De Waal Malefijt MC, Verdonschot N. Sit-tostand movement as a performance-based measure for patients with total knee arthroplasty. PhysTher 2010;90(2):14956. [PubMed: 20007664]

25. Hurwitz DE, Ryals AR, Block JA, Sharma L, Schnitzer TJ, Andriacchi TP. Knee pain and joint loading in subjects with osteoarthritis of the knee. J Orthop Res 2000;18(4):572-9. [PubMed: 11052493]

26. Asay JL, Mundermann A, Andriacchi TP. Adaptive patterns of movement during stair climbing in patients with knee osteoarthritis. J Orthop Res. 2008

27. Mizner RL, Snyder-Mackler L. Altered loading during walking and sit-to-stand is affected by quadriceps weakness after total knee arthroplasty. J Orthop Res 2005;23(5):1083-90. [PubMed: 16140191]

28. Harato K, Nagura T, Matsumoto H, Otani T, Toyama Y, Suda Y. Extension Limitation in standing Affect WeightBearing asynnetry After Unilateral Total knee Arthroplasty. J Arthroplasty. 2009 